\title{
Seasonal changes in the dynamic state of water for excised cherry branches (Prunus lannesiana) observed using dedicated micro-magnetic resonance imaging
}

\author{
Hiromi Kano ${ }^{1}$, Mika Koizumi ${ }^{2, *}$ \\ ${ }^{1}$ Oak-Hill Georgic Patch-Work Laboratory, Chiba, Japan \\ ${ }^{2}$ Research Institute for Science and Engineering, Waseda University, Tokyo, Japan
}

Email address:

toradaiou@gamma.ocn.ne.jp (H. Kano), m.koizumi4@kurenai.waseda.jp (M. Koizumi)

\section{To cite this article:}

Hiromi Kano, Mika Koizumi. Seasonal Changes in the Dynamic State of Water for Excised Cherry Branches (Prunus lannesiana) Observed Using Dedicated Micro-Magnetic Resonance Imaging. Plant. Vol. 2, No. 6, 2014, pp. 60-67. doi: 10.11648/j.plant.20140206.11

\begin{abstract}
Seasonal changes in the dynamic state of water for cherry (Prunus lannesiana), a deciduous broad-leaved tree, were studied by combined $\mathrm{k}$-space and q-space imaging using dedicated magnetic resonance imaging (MRI) with a 1.0-T permanent magnet. Water amounts, diffusion coefficients and transpiration were examined for excised branches cut from a tree with and

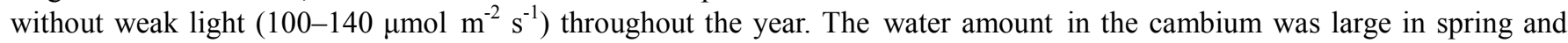
summer, decreased in autumn, and decreased further in winter. There were three components in the diffusion coefficient of the branch. The second component of the diffusion coefficient ascribed to the cambium did not fluctuate notably throughout the year, despite marked alternation in water amounts. However, diffusion coefficients in the secondary xylem, the primary component, were elevated in summer and decreased in winter. Upward water flow was restricted in the secondary xylem, and the positions where large flow was detected coincided with places exhibiting high diffusion coefficients and the arrangements of vessels. Total transpiration exhibited a tendency similar to that of the diffusion coefficients; however, total transpiration declined to zero when the plant had no leaf, whereas the diffusion coefficient decreased to $60 \%$ of the maximum but did not decrease further. Light-enhanced transpiration related to potential photosynthetic activity increased in spring as the leaves sprouted and grew, considerably decreased in summer, decreased to one third of the maximum in autumn, and was not detected in winter. Measurement of the dynamic state of water for the excised branches will provide useful information for better understanding of the phenological changes of tree physiology.
\end{abstract}

Keywords: Cherry Tree (Prunus lannesiana), Dedicated MRI, Dynamic State of Water, Excised Branches, Seasonal Changes, Transpiration

\section{Introduction}

The status of water changes in tree branches in different seasons due to fluctuation of temperature, moisture, and other climate conditions; it may also be influenced by intrinsic conditions of plants growth [1-4]. The amount and movement of cell-associated water are related to metabolic rate and growth [5-7]. Transpiration of water is essential for organizing the system of plants (e.g., transport of water between tissues, uptake of nutrients and other materials, and cooling of the plant body) and is related to photosynthesis [8]. Magnetic resonance imaging (MRI) has been used to investigate water in tree plants [9-14]. Based on studies of water in plant tissues using MRI, distribution of water is presented using ${ }^{1} \mathrm{H}-\mathrm{NMR}$ images [15], spatial movement of water is measured as diffusion coefficients [16-17], and flowing water and flow velocity are examined by dynamic imaging methods [18-23]. The combined $\mathrm{k}$-space and q-space imaging method [23] has been used to investigate xylem and phloem flow in plants stems [24-26]. Probes for inspecting the physiology of plant tissues, amounts and diffusion coefficients of cell-associated water in tissues, and flow rates of water in the plant vasculature are simultaneously obtained using this method.

The dynamic state of water in differentiated tissues was studied by combined $\mathrm{k}$-space and q-space imaging for excised Ligustrum lucidum branches in the previous paper [27]. A small, dedicated MRI with a permanent magnet and an MRI spectrometer, the operation system of which was written by 
Windows for personal computers [28-29], was used. Repetition time (TR) for radiofrequency of the spin-echo sequence was shortened in order to obtain a set of data within the available measurement time, as a result, calibration using standard phantoms was necessary for quantitative estimation. In the current investigation, this method was applied for excised cherry branches (Prunus lannesiana) to examine the phenological changes in tree physiology. This study provided useful information about the properties of cell-associated water in the cambium corresponding to the annual growth of trees, as well as in the parenchyma of the secondary xylem concerning long-distance transport of water.

\section{Materials and Methods}

\subsection{Plant Materials}

Similar branches were taken from a cherry tree (Prunus lannesiana) on the campus of Waseda University from June 23, 2012 to June 1, 2013. Table 1 lists the dates of experiments, the weight of leaves, and the amount of water uptake measured using a measuring cylinder. The tree flowered in early April with simultaneous sprouting of leaves; the leaves grew from April to June and had fallen with browning by the last of November or the beginning of December. Excised branches were trimmed and incubated in distilled water for an hour to acclimate them to room conditions and were then used for the measurement.

Table 1. Dates of experiment, leaf weight, and water uptake

\begin{tabular}{lllll}
\hline Date & Serial day & Leaf weight $(\mathbf{g})$ & Water uptake Light $(\mathbf{m l})$ & Water uptake Dark $(\mathrm{ml})$ \\
\hline June 1 & 1 & - & - & - \\
June 23 & 23 & 145 & 28.0 & 17.5 \\
July 7 & 37 & 118 & 27.5 & 15.5 \\
September 8 & 100 & 120 & 21.5 & 11.0 \\
October 27 & 149 & 111 & 19.0 & 11.0 \\
November 24 & 177 & 128 & 29.0 & 18.5 \\
February 2 & 247 & 0 & 0 & 0 \\
April 20 & 324 & 89 & 20.0 & 10.0 \\
June 1 & 365 & 153 & 27.0 & 12.0 \\
\hline
\end{tabular}

\subsection{Observation of Morphology Using Optical Microscope}

Cross-sections of a young branch $8 \mathrm{~mm}$ in diameter were stained with toluidine blue and observed with an optical microscope (Olympus, Tokyo, Japan). Micrographs were taken using a digital camera (Nikon, Coolpix 995, Tokyo, Japan).

\subsection{MRI Apparatus and Measurements}

The branch was inserted into a measuring cup under the magnet through the detector of an MRI apparatus. Measurements were carried out with and without light. Three light sources holding three LED lamps of different light qualities were used. The light intensity ranged from 100 to $140 \mu \mathrm{mol} \mathrm{m} \mathrm{m}^{-2} \mathrm{~s}^{-1}$ on the center leaves of the branch. Light stands were made of wood, vinyl rope, and packing tape by adjusting the geometry of the lamps to the shape of the branch in each experiment. A dark room was made using black curtains.

A dedicated MRI equipped with a 1.0-Tesla (T) permanent magnet with a 60-mm pole gap (Neomax Engineering Co., Ltd., Gunma, Japan) and a spectrometer based on a Windows personal computer (MRTechnology Inc., Tsukuba, Japan) [28, 29] were used. The detector had a $30-\mathrm{mm}$ diameter solenoid coil, and the temperature of the measurement cell was controlled at $28^{\circ} \mathrm{C}$.

Diffusion coefficients were obtained by the equation of Stejskal and Tanner [30]. NMR flow imaging was carried out by the combined k-space and q-space imaging method [23] with appropriate modifications. A short TR for radio-frequency projection was employed to reduce measurement time. Diffusion coefficients and flow velocities were determined with calibration curves using standard phantoms because the signals of high-mobility water might be saturated due to the short TR. Experiments were conducted according to the procedures described in the previous paper [27].

A data set of 2D images applied with 16 stepping magnitudes of pulsed-field gradients (PFG) from $-\mathrm{G}$ to $+\mathrm{G}$ was collected; a PFG pair was applied before and after the 180-degree radio-frequency pulse at each image acquisition by the spin-echo 2D-FT method. TR was set at $1 \mathrm{~s}$, TE at 40.4 $\mathrm{ms}$, duration of PFG application $(\delta)$ at $8 \mathrm{~ms}$, and diffusion period $(\Delta)$ at $25 \mathrm{~ms}$. Data were acquired using a $128 \times 64$ matrix, and images were recreated on a $128 \times 128$ matrix. The resulting spatial resolution was $234 \mu \mathrm{m}$ with a 3.6 -mm-thick slice. Diffusion coefficient images were calculated using the set of 2D images. The series of image data applied with PFG was then compiled into a 3D-image datum and Fourier transformed after zero-filling to obtain a flow-encoded image and dynamic displacement profiles.

Images were analyzed using the ImageJ program (a public-domain JAVA image-processing program (version $1.43 \mathrm{u}$ ), available on the Internet at http://rsb.info.nih.gov/ij/).

\section{Results}

\subsection{Morphology of a Cherry Branch}

Cross-sections of a young cherry branch are presented in Fig. 1. (A) Around the epidermal layer. (B) At center of the secondary xylem. (C) Near the pith. A large number of vessels 
were observed in the secondary xylem (c), and radial strands passed through the secondary xylem to the cortex in the epidermal layer (a) outside the cambium (b) in Fig. 1 (A and B). In addition, concentric circles with continuing vessels (d) were observed just under the cambium (Fig. 1A) and across the radial strands with uneven separations in the secondary xylem (Fig. 1C). It is noteworthy that many cavities were irregularly dispersed between the circles in the secondary xylem (c).

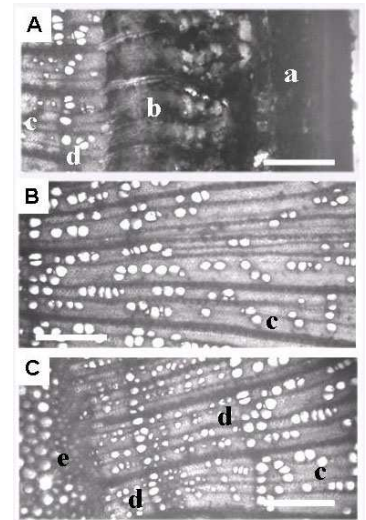

Fig. 1. Morphology of a cherry branch. (A) Around the epidermal layer. (B) Center of the secondary xylem. (C) Near the pith. (a) The epidermal layer. (b) The cambium. (c) The secondary xylem. (d) Continuous concentric circle of vessels. (e) The primary xylem near the pith. Scale bar is $250 \mu \mathrm{m}$

\subsection{Seasonal Changes in the ${ }^{1} H$-NMR Image and the Diffusion Coefficient Image of Branches}

Figure 2 presents changes in the ${ }^{1} \mathrm{H}-\mathrm{NMR}$ image (top row) and in the diffusion coefficient image (bottom row) with experiment times during the different seasons. Leaves fell until the beginning of December and sprouted during the first week of April; therefore, the sample on February 2 had no leaves. The results in the ${ }^{1} \mathrm{H}-\mathrm{NMR}$ and diffusion coefficient images of cherry branches in spring and summer were similar to those of Ligustrum lucidum branches reported in the previous paper [27]. Marked change in signal intensity in the ${ }^{1} \mathrm{H}-\mathrm{NMR}$ images representing the water amounts was observed for the cambium; however, no definite fluctuation was observed for the secondary xylem throughout the seasons (Fig. 2 top). Water was unevenly distributed by forming concentric circles in the secondary xylem for all branches. Signal intensities per area in the cambium and the secondary xylem were measured separately (Fig. 3). Water amounts in the cambium were high in spring and summer but had decreased to $50 \%$ of the maximum by September 8 and then further declined below $30 \%$ by February 2 . In contrast, water amounts in the secondary xylem were rather constant at $50 \%$ of the maximum in the cambium except for a slight increase in spring.

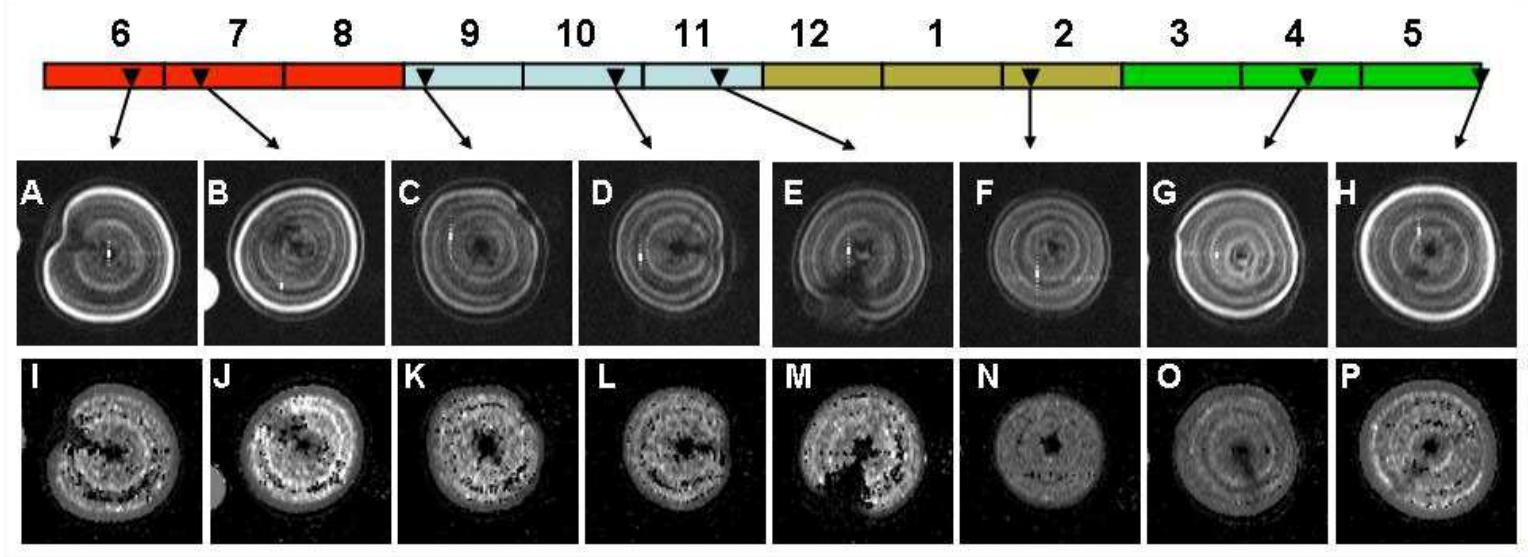

Fig. 2. Seasonal changes in ${ }^{I} H$-NMR images (top row) and in diffusion coefficient images (bottom row). The color bar above the images indicates experiment periods. Red is summer, light blue is autumn, dark brown is winter, and green is spring. Figures are months, and the first day is June 1. Experiment dates: A and I, June 23; B and J, July 7; C and K, September 8; D and L, October 27; E and M, November 24; F and N, February 2; G and O, April 20; and H and P, June, 1.

Attenuation of averaged signals in the images was plotted against the square of PFG on a logarithmic scale for the experiment on July 7 (Fig. 4). A straight line was obtained for the standard phantom, the slope of which corresponds to the diffusion coefficient of pure water $\left(2.3 \times 10^{-5} \mathrm{~cm}^{2} \mathrm{~s}^{-1}\right)$. The plot for the branch broke into three lines, indicating the existence of three components in the diffusion coefficient. The values were very low in the epidermal layer, and values for the cambium were lower than those for the secondary xylem in the diffusion coefficient images (Fig. 2 bottom). The diffusion coefficients in the secondary xylem varied with position, and high-value signals drew concentric circles just under the cambium and in the middle of the secondary xylem.

The first and second components of the diffusion coefficients are graphed with experiment times in Fig. 5. The first component ranged from $1.5 \times 10^{-5} \mathrm{~cm}^{2} \mathrm{~s}^{-1}$ in winter to 2.5 $\times 10^{-5} \mathrm{~cm}^{2} \mathrm{~s}^{-1}$ in summer, the second component ranged from $0.6 \times 10^{-5} \mathrm{~cm}^{2} \mathrm{~s}^{-1}$ to $1.0 \times 10^{-5} \mathrm{~cm}^{2} \mathrm{~s}^{-1}$, and the third component was omitted because of very low values. The first component reached higher value than that of pure water $\left(2.3 \times 10^{-5} \mathrm{~cm}^{2} \mathrm{~s}^{-1}\right)$ in summer but declined to $60 \%$ of the maximum in winter. The second component did not exhibit a direct response to seasons. 


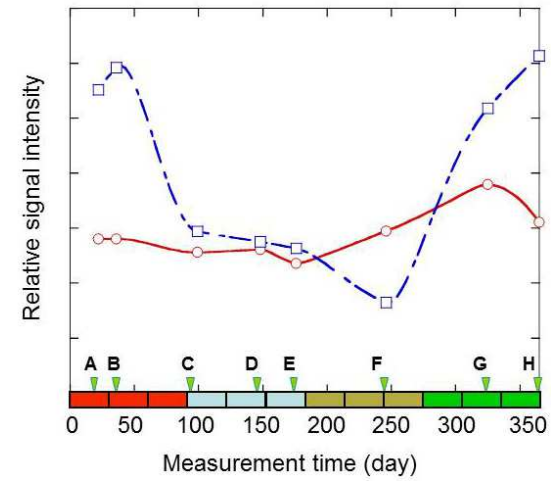

Fig. 3. Seasonal changes in signal intensities of the cambium and the secondary xylem in ${ }^{1} H$-NMR images. Signal intensities were measured (Fig. 2) and divided by areas of the cambium and the xylem. Blue squares with a dashed line denote the cambium. Red circles with a solid line denote the secondary xylem. Experiment times are the same as in Fig. 2. The horizontal axis is serial day as indicated in Table 1.

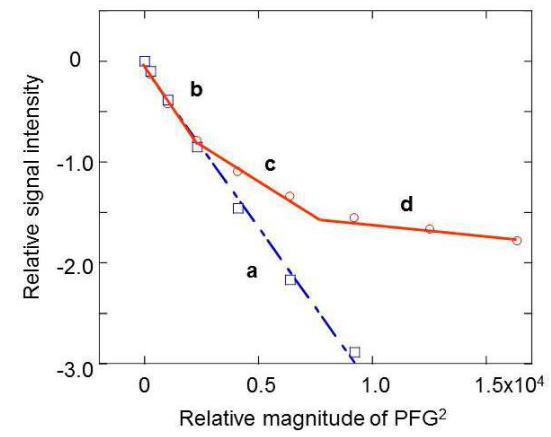

Fig. 4. Effects of pulsed-field gradients on the logarithmic plot of signal attenuation for the stationary phantom and a tree branch. Plotted data of July 7. (a) The stationary phantom. (b, $c$ and d) A tree branch. The slope of the logarithmic plot for the stationary phantom is $2.3 \times 10^{-5} \mathrm{~cm}^{2} \mathrm{~s}^{-1}$ at $28^{\circ} \mathrm{C}$, the diffusion coefficient of pure water.

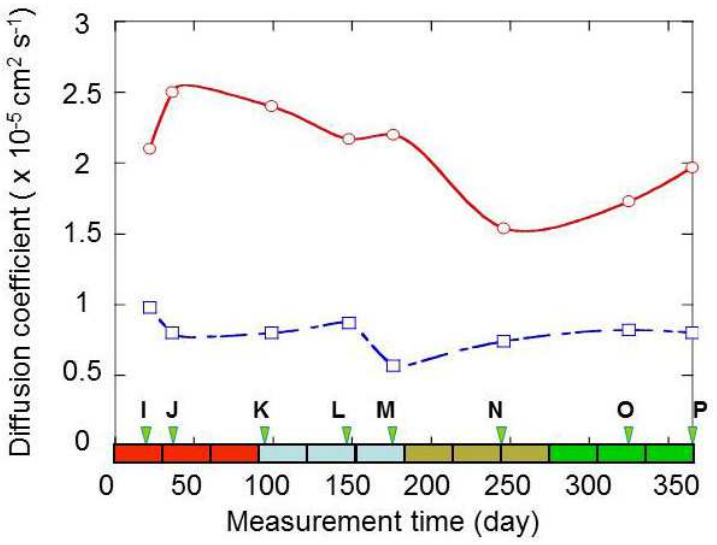

Fig. 5. Seasonal changes in diffusion coefficients for cherry branches. Three components were detected in Fig. 4, and the first and the second components were plotted. Red circles with a solid line denote the first component. Blue squares with a dashed line denote the second component. Experiment times are the same as in Fig. 2, and the horizontal axis is serial day as indicated in Table 1.

\subsection{Seasonal Changes in the Flow-Encoded Image of Branches}

Flow-encoded images in the light (top row) and light-enhanced flow images (bottom row) are presented in Fig. 6 . The flow-encoded images represent whole transpiration where signals were restricted in the secondary xylem (Fig. 6 top). Strong signals formed concentric circles that roughly coincided with those observed in the diffusion coefficient images in the bottom portion of Fig. 2. The areas without signals in the flow-encoded images were probably due to branching.

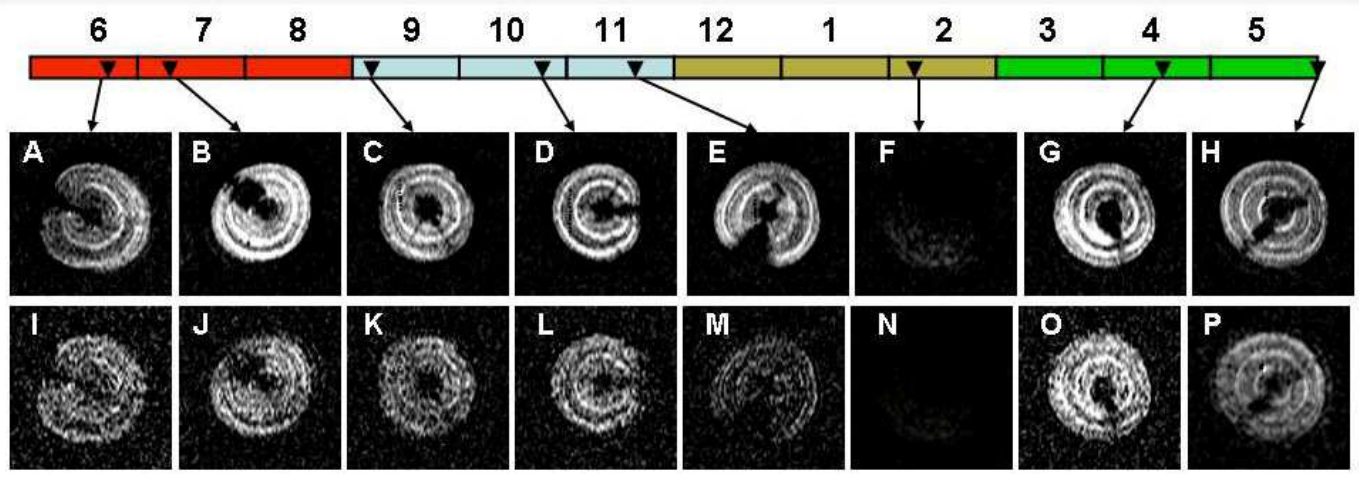

Fig. 6. Seasonal changes of flow-encoded images in the light (top row) and light-enhanced flow images (bottom row). Light-enhanced images were calculated by subtracting a flow-encoded image in the dark from that in the light. The experiment times are the same as in Fig. 2.

Whole transpiration (Fig. 6 top) per area of the xylem increased from spring to summer, and decreased to two thirds in autumn. No flow was detected in winter, as leaves had fallen (Fig. 7). Dark transpiration was calculated based on flow-encoded images in the dark, which did not coincide with that of whole transpiration in the light (Fig. 7). Changes in flow amounts measured using MRI tended to be similar to that obtained using a measuring cup; however, the reason for the discrepancy between light and dark conditions was unclear. Light-enhanced flow images (Fig. 6 bottom) representing flowing spins stimulated by light were calculated by subtracting the flow-encoded images in the dark from the flow-encoded images in the light; then the images were normalized by the amount of leaves (Table 1). Concentric circles were also observed in the light-enhanced flow images. Flow velocity was calculated using dynamic displacement profiles [23] (Fig. 8) at positions where intense signals were observed on the flow-encoded images (Fig. 6 top). Flow velocities are presented together with light-enhanced flow per area of the secondary xylem in Fig. 9. Light-enhanced 


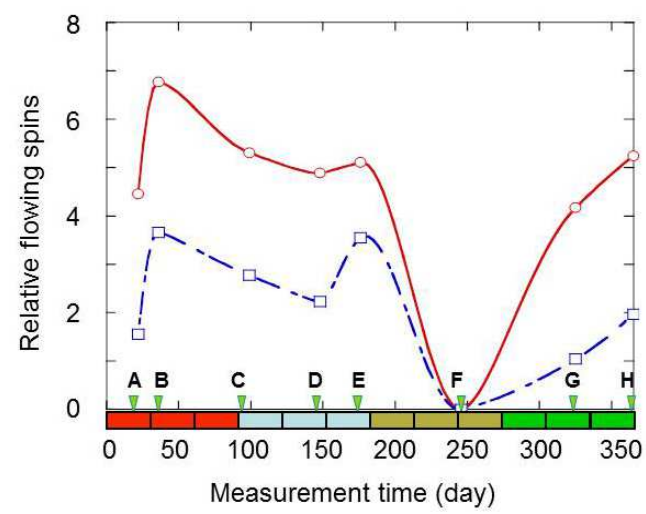

Fig. 7. Seasonal changes in flow amounts of whole transpiration and that in the dark. Red circles with a solid line denote flow amounts indicated by spin populations per area in the light. Blue squares with a dashed line denote flow amounts indicated by spin populations per area in the dark. Experiment times are the same as in Fig. 2, and the horizontal axis is serial day as indicated in Table 1.

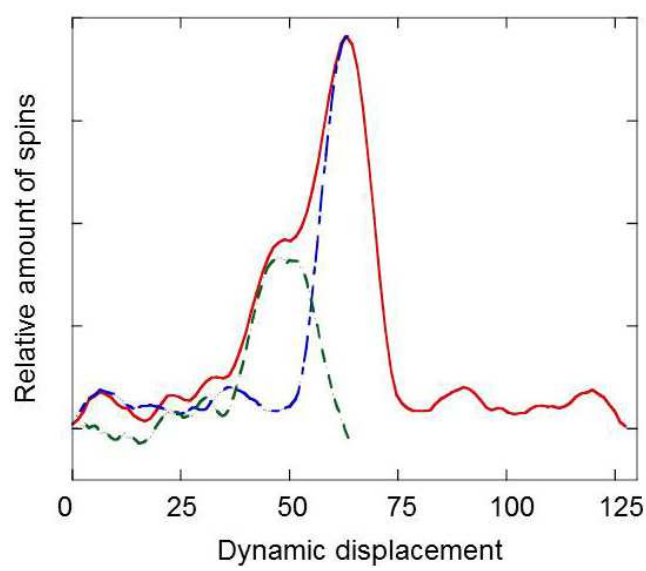

Fig. 8. Dynamic displacement profile for the branch on July 7. Dynamic displacement profile (solid line) in q-space at the upper center of the second circle with intense signal in Fig. $6 \mathrm{~B}$ is presented. The displacement shifts to the left, so the flow is upward. The right-side curve from the peak top was reversed (blue dashed line) and then subtracted from the left-side curve (red solid line) to obtain the dynamic displacement of the flow water molecules (green dotted line)

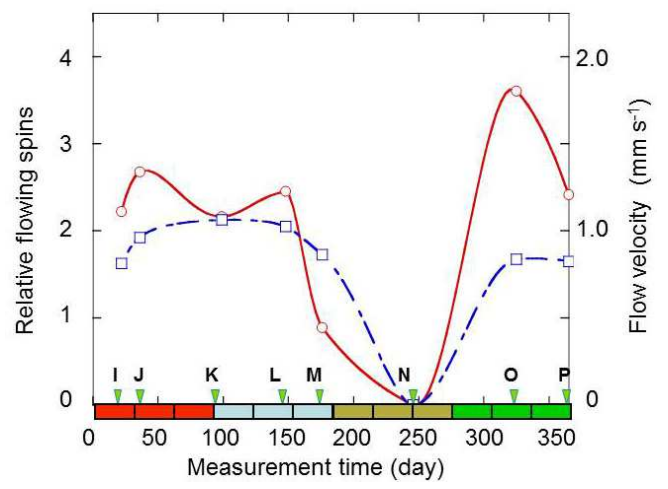

Fig. 9. Seasonal changes of light-enhanced flow amounts and flow velocity. Red circles with a solid line denote light-enhanced flow amounts indicated by spin populations normalized by area of the secondary xylem and leaf weight. Blue squares with a dashed line denote flow velocity calculated using dynamic displacement profiles as presented in Fig. 8. Experiment times are the same as in Fig. 2, and the horizontal axis is serial day as indicated in Table 1. transpiration was high in spring when leaves sprouted and decreased to two thirds with full expansion of the leaves in summer [2]. Light-enhanced transpiration was maintained while the leaves were green, decreased when the leaves turned brown, and stopped when the tree had no leaves. In contrast, flow velocity ranged from $0.65 \pm 0.1$ to $0.85 \pm 0.2 \mathrm{~mm} \mathrm{~s}^{-1}$ and did not fluctuate regardless of changes in flow amount (Fig. 9) while the tree had leaves.

\section{Discussion}

The dynamic state of water was analyzed for cherry branches in regard to phenology (Figs. 2 and 6). ${ }^{1} \mathrm{H}-\mathrm{NMR}$ images representing water amounts (Fig. 2 top) indicate the mass of matrix for metabolism or protoplasm, while diffusion coefficient images (Fig. 2 bottom) correspond to the rate of metabolism [7, 17]. Flow-encoded images (Fig. 6) related to transpiration are involved in maintaining a plant system as an organic whole $[20,21,24]$. Therefore, these parameters are thought to be suitable probes for investigating the physiology of tree plants [26, 31].

The cambium and the secondary xylem exhibited phenologically different tendencies in water amounts and diffusion coefficients. Observed alterations in water amounts in the cambium (Fig. 2 top) were characteristic of the annual cycle of tree growth $[1,3,32]$ : large in spring and summer, less in autumn, and even less in winter (Fig. 3). The second component of diffusion coefficient (Figs. 4 and 5) is water in the cambium based on the profile and histogram of the diffusion coefficient image of the branch on July 7 (Fig. 10). The dividing cells and enlarging cells in the cambium are filled with functional structures and macromolecular compounds such as starch grains required for synthesizing biomaterials [4], and obstacles for the movement of cell-associated water $[5,31]$. Thus, water mobility was not so high that the metabolic rate seemed low even in summer; nevertheless, the cambium is active enough to grow. Reduction of water in autumn and winter indicates that control of cambial activity is accompanied by retardation in the mass of matrix for metabolism or protoplasm, which is interpreted by the facts that solid materials accumulate in the phloem cells while cell-walls are lignified to generate secondary walls in xylem-side cells during dormancy $[4,32]$.

Water amounts were rather constant in the secondary xylem, except for a slight increase in spring (Fig. 3), when the light-enhanced transpiration increased greatly (Fig. 9) [2]. The first component of the diffusion coefficient (Figs. 4 and 5) is ascribed to water in the xylem (Fig. 10); therefore, the metabolism of parenchyma cells in the secondary xylem is high in summer and low in winter (Fig. 5). The metabolic rate was a few times higher than that of the cambium but not uniform in the secondary xylem. Superposition of the diffusion coefficient image and the flow-encoded image on the ${ }^{1}$ H-NMR image of the branch on July 7 (Fig. 11) indicated that the concentric circles of water signals (Fig. 11A) coincide with positions exhibiting high diffusion coefficients (Fig. 11B) and large water flow (Fig. 11C). Circles with high signal 
intensities were suited with the arrangement of vessels: concentrated cavities just under the cambium (Fig. 1A) and continuous chains of cavities with unequal radial separations (Fig. 1C) in the secondary xylem. The vessels include active parenchyma cells to sustain transpiration. However, there was no direct connection between the water flow (Fig. 7) and the metabolic rate in parenchyma cells (Fig. 5). One obvious discrepancy is that the diffusion of cell-associated water did not stop (Fig. 5) even when no upward flow of water was detected (Fig. 7), probably due to intra- and inter-cellular transport of water.
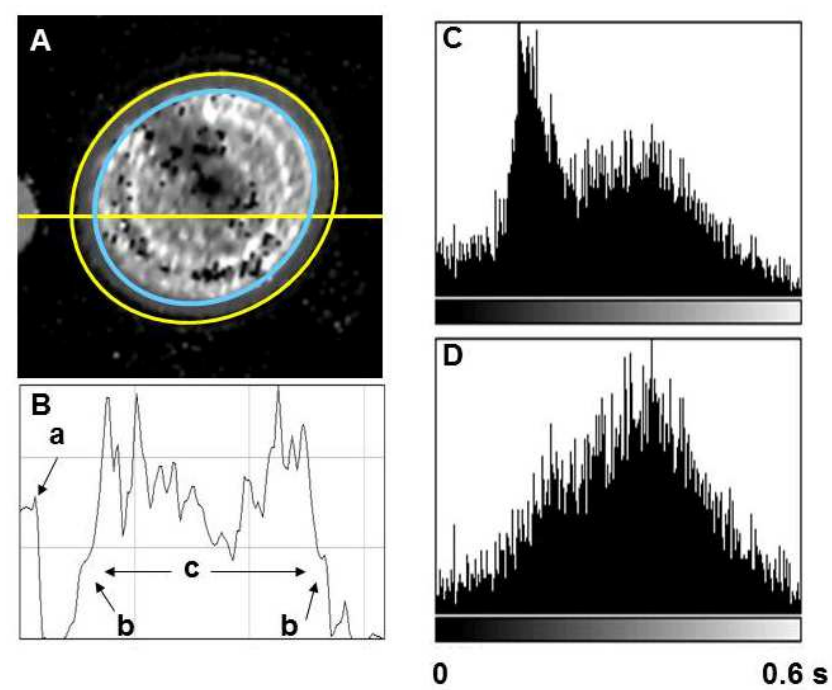

Fig. 10. Diffusion coefficient image, signal profile, and histograms of signals of the area including the cambium and the area without the cambium. (A) Diffusion coefficient image on July 7. (B) Signal profile taken at a yellow line. (a) Stationary phantom. (b) The cambium. (c) The secondary xylem. (C) Signal histogram of the area including the cambium, indicated by a yellow circle. (D) Signal histogram of the area without the cambium, indicated by a blue circle.
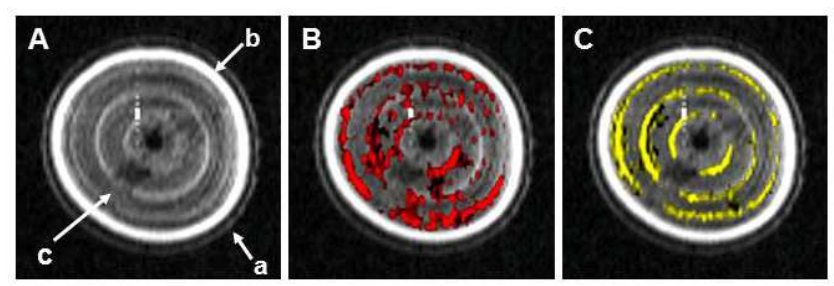

Fig. 11. ${ }^{I} H-N M R$ image depicting morphology, and superposition of a diffusion coefficient image and a flow-encoded image in the light for a branch on July 7. (A) $A^{I} H$-NMR image. (a) The epidermal layer. (b) The cambium. (c) The secondary xylem. (B) Strong signals of the diffusion coefficient image in Fig. 2J, denoted by red, and (C) strong signals of the flow-encoded image in Fig. 6B, denoted by yellow, were superposed on the ${ }^{I} H$-NMR image.

Physiological involvement in changes of flow-encoded images (Fig. 6 top) including both transpiration driven by light and that in the dark (Fig. 7) cannot be clearly interpreted because the flow in the dark is affected by internal conditions, growth stage, nutritional supply [2], and the endogenous physiological situation [3] of the branches. However, light-enhanced flow or transpiration stimulated by light characteristically tended to be dominated by leaf conditions: high in spring when leaves were developing, reduced with saturation in leaf growth until summer, low when leaves turned brown in autumn, and diminished in winter without leaves (Fig. 9). In the current investigation, weak light (100-140 $\mu \mathrm{mol} \mathrm{m} \mathrm{m}^{-2} \mathrm{~s}^{-1}$ ) was used in a mildly air-conditioned room to avoid severe environmental stress. Therefore, light-enhanced water flow is thought to be regulated by potential photosynthetic activity through stomatal diffusion-resistance [8]; thus, photosynthetic capacity is closely related to leaf growth [2]. Flow velocities from 0.65 to $0.85 \mathrm{~mm} \mathrm{~s}^{-1}$ (Figs. 8 and 9) are at the level of those determined for excised Ligustrum lucidum branches [27], the seasonal change of which was not parallel to whole transpiration (Fig. 7) and light-enhanced transpiration (Fig. 9).

This result was obtained in a room with low light intensity and a set temperature using excised cherry tree branches. Thus, seasonal changes in the dynamic state of water for tree branches in natural conditions were not determined, and these results are not suitable for direct analogy with other plants. Nevertheless, ${ }^{1} \mathrm{H}-\mathrm{NMR}$ images, diffusion coefficient images, and flow-encoded images obtained by a combined k-space and q-space imaging method, using a small, dedicated MRI apparatus equipped with a permanent magnet and controlled on a Windows system, provided useful means for examining the phenological physiology of trees such as changes in the cambium activity (Fig. 3), and the fluctuation of metabolic rate (Fig. 5) and transpiration in the secondary xylem (Figs. 7 and 9). This method can be used for intact plants in the field. Approaches have already begun [26, 33-36]; however, some problems remain. A matter of most importance is the drastic reduction of magnet weight. A low-field MRI equipped with a 0.2-T magnet with a $160-\mathrm{mm}$ pole gap usable for standing trees was stable enough to attain good quality images [37]. However, the 500-kg magnet is heavy enough to pack the ground and thus harm root growth. In this context, devices lighter than several-ten $\mathrm{kg}$, the level of human weight are desired for applying MRI to intact trees in open fields [38]. Another issue is the high stabilization of low-field magnets with large pole gaps against the fluctuation of ambient conditions, which is essential for obtaining quantitative images required for combined k-space and q-space imaging [23].

\section{Reference}

[1] F.J. Alfieri and R.F. Evert, "Seasonal development of the secondary phloem in Pinus." American Journal of Botany, 1968. 55: 518-528.

[2] P.B. Reich, M.B. Walters and D.S. Ellsworth, "Leaf age and season influence the relationships between leaf nitrogen, leaf mass per area and photosynthesis in maple and oak trees." Plant, Cell and Environment, 1991. 14: 251-259.

[3] E.J. Mellerowicz, W.K. Coleman, R.T. Riding and C.H.A. Little, "Periodicity of cambial activity in Abies balsamea. I. Effects of temperature and photoperiod on cambial dormancy and frost hardiness." Physiologia Plantarum, 1992. 85: 515-525. 
[4] J.J. Farrar and R.F. Evert, "Seasonal changes in the ultrastructure of the vascular cambium of Robinia pseudoacacia." Trees, 1997. 11: 191-202.

[5] C.F. Hazlewood, D.C. Chang, D. Medina, G. Cleveland and B.L. Nichols, "Distinction between the preneoplastic and neoplastic state of murine mammary glands." Proceedings of the National Academy of Science, USA, 1972. 69: 1478-1480.

[6] N. Ishida, H. Kano, T. Kobayashi, H. Hamaguchi and T. Yoshida, "Estimation of biological activities by NMR in soybean seeds during maturation." Agricultural and Biological Chemistry, 1987. 51: 301-307.

[7] H. Kano, N. Ishida, T. Kobayashi and M. Koizumi, " ${ }^{H} \mathrm{H}-\mathrm{NMR}$ imaging analysis of changes of free water distribution in barley and soybean seeds during maturation." Japanese Journal of Crop Science, 1990. 59: 503-509.

[8] P. Gaastra, "Photosynthesis of crop plants as influenced by light, carbon dioxide, temperature, and stomatal diffusion resistance." $1959 . \quad$ pp. 1-68. Mededelingen, Landbouwhogeschool, 59, 13; Wageningen Veenman

[9] M. Koizumi, N. Ishida, H. Takagishi, K. Shirata and H. Kano, "Observation of water and $\mathrm{Na}^{+}$in tissues of the Bruguiera gymnorrhiza by ${ }^{1} \mathrm{H}-$ and ${ }^{23} \mathrm{Na}-\mathrm{NMR}$ imaging." The Botanical Magazine, Tokyo, 1992. 105: 1-11.

[10] J.S. MacFall and G.A. Johnson, "The architecture of plant vasculature and transport as seen with magnetic resonance microscopy." Canadian Journal of Botany, 1994. 72: 1561-1573.

[11] N.M. Holbrook, E.T. Ahrens, M.J. Burns and M.A. Zwieniecki, "In vivo observation of cavitation and embolism repair using magnetic resonance imaging." Plant Physiology, 2001. 126: 27-31.

[12] M.J. Clearwater and C.J. Clark, "In vivo magnetic resonance imaging of xylem vessel contents in woody lianas." Plant, Cell and Environment, 2003. 26, 1205-1214.

[13] T. Umebayashi, K. Fukuda, T. Haishi, R. Sotooka, S. Zuhair and K. Otsuki, "The developmental process of xylem embolisms in pine wilt disease monitored by multipoint imaging using compact magnetic resonance imaging." Plant Physiology, 2011. 156: 943-951.

[14] V. De Schepper, D. van Dusschoten, P. Copini, S. Jahnke and K. Steppe, "MRI links stem water content to stem diameter variations in transpiring trees." Journal of Experimental Botany, 2012. 63: 2645-2653.

[15] H. Kano, N. Ishida, H. Takagishi, K. Shirata and M. Koizumi, "Tracing effects of $\mathrm{Na}^{+}$on morphology, phosphate metabolism and accumulated compounds of a sugar beet root by NMR." Japanese Journal of Crop Science, 1993. 62: 95-104.

[16] C.D. Eccles, P.T. Callaghan and C.F. Jenner, "Measurement of the self-diffusion coefficient of water as a function of position in wheat grain using nuclear magnetic resonance imaging." Biophysical Journal, 1988. 53: 77-81.

[17] N. Ishida, H. Ogawa and H. Kano, "Diffusion of cell-associated water in ripening barley seeds." Magnetic Resonance Imaging, 1995. 13: 745-751.

[18] Y. Xia, V. Sarafis, E.O. Campbell and P.T. Callaghan, "Non invasive imaging of water flow in plants by NMR microscopy." Protoplasma, 1993. 173: 170-176.
[19] P.T. Callaghan, W. Köckenberger and J.M. Pope, "Use of difference propagators for imaging of capillary flow in the presence of stationary fluid." Journal of Magnetic Resonance, Series B, 1994. 104: 183-188.

[20] E. Kuchenbrod, E. Kahler, F. Thürmer, R. Deichmann, U. Zimmermann and A. Haase, "Functional magnetic resonance imaging in intact plants - quantitative observation of flow in plant vessels." Magnetic Resonance Imaging, 1998. 16: 331-338.

[21] M. Rokitta, U. Zimmermann and A. Haase, "Fast NMR flow measurements in plants using FLASH imaging." Journal of Magnetic Resonance, 1999. 137: 29-32.

[22] T.W.J. Scheenen, D. van Dusschoten, P.A. de Jager and H. Van As, "Microscopic displacement imaging with pulsed field gradient turbo spin-echo NMR." Journal of Magnetic Resonance, 2000. 142: 207-215.

[23] P.T. Callaghan "Principles of nuclear magnetic resonance microscopy." 1991. Oxford Clarendon Press

[24] W. Köckenberger, J.M. Pope, Y. Xia, K.R. Jeffrey, E. Komor and P.T. Callaghan, "A non-invasive measurement of phloem and xylem water flow in castor bean seedlings by nuclear magnetic resonance microimaging." Planta, 1997. 201: 53-63.

[25] C.W. Windt, F.J. Vergeldt, P.A. de Jager and H. Van As, "MRI of long-distance water transport: a comparison of the phloem and xylem flow characteristics and dynamics in poplar, castor bean, tomato and tobacco." Plant, Cell and Environment, 2006. 29: $1715-1729$.

[26] H. Van As and J. van Duynhoven, "MRI of plants and foods." Journal of Magnetic Resonance, 2013. 229: 25-34.

[27] H. Kano and M. Koizumi, "Dynamic state of water in excised Ligustrum lucidum branches observed by dedicated micro-magnetic resonance imaging." Plant, 2014. 2: 33-40. doi: 10.11648/j.plant.20140203.12.

[28] M. Koizumi, F. Ihara, K. Yaginuma, H. Kano and T. Haishi, "Observation of the peach fruit moth, Carposina sasakii, larvae in young apple fruit by dedicated micro-magnetic resonance imaging." Journal of Insect Science, 2010. 10: 145, available on line: insectscience.org/10.145

[29] M. Koizumi and H. Kano, "Water entry in dry soybeans at imbibition observed by dedicated micro-magnetic resonance imaging." American Journal of Biology and Life Sciences, 2014. 2: 6-11.

[30] E.O. Stejskal and J.E. Tanner, "Spin diffusion measurements: spin echoes in the presence of a time-dependent field gradient." The Journal of Chemical Physics, 1965. 42: 288-292.

[31] N. Ishida, M. Koizumi and H. Kano, "The NMR microscope: a unique and promising tool for plant science." 2000. Annals of Botany, 86: 259-278.

[32] L. Murmanis, "Structural changes in the vascular cambium of Pinus strobus L. during an annual cycle." Annals of Botany, 1971. 35: 133-141.

[33] M. Rokitta, E. Rommel, U. Zimmermann and A. Haase, "Portable nuclear magnetic resonance imaging system." Review of Scientific Instruments, 2000. 71: 4257-4262.

[34] E. Danieli, J. Mauler, J. Perlo, B. Blümich and F. Casanova, "Mobile sensor for high resolution NMR spectroscopy and imaging.” Journal of Magnetic Resonance, 2009. 198: 80-87. 
[35] T. Kimura, Y. Geya, Y. Terada, K. Kose, T. Haishi, H. Gemma and Y. Sekozawa, "Development of a mobile magnetic resonance imaging system for outdoor tree measurements." Review of Scientific Instruments, 2011, 82: 053704; doi: 10.1063/1.3589854

[36] C.W. Windt, H. Soltner, D. van Dusschoten, and P. Blümler, “A portable Halbach magnet that can be opened and closed without force: the NMR-CUFF.” Journal of Magnetic Resonance, 2011. 208: 27-33.
[37] T. Haishi, H. Koizumi, T. Arai, M. Koizumi and H. Kano, "Rapid detection of infestation of apple fruits by the peach fruit moth, Carposina sasakii Matsumura, larvae using a 0.2-T dedicated magnetic resonance imaging apparatus." Applied Magnetic Resonance, 2011. 41: 1-18.

[38] M. Jones, P.S. Aptaker, J. Cox, B.A. Gardiner and P.J. McDonald, "A transportable magnetic resonance imaging system for in situ measurements of living trees: The Tree Hugger." Journal of Magnetic Resonance, 2012. 218: 133-140. 